\title{
Enhancing Onion Production and Productivity through Introduction of Seed Production Techniques in Central Zone of Tigray Region, Ethiopia
}

\author{
Yamane Kahsay, Horticulture Associate researcher \\ Axum Agricultural Research Center, Axum, Ethiopia
}

\begin{abstract}
The main reason of low production and productivity is restricted use of inputs, notably improved seeds and fertilizers. Different vegetable seeds are imported which results in different problems like disease outbreak, timely unavailability, costly and so on. The demand of vegetable seed is increasing from time to time. Though vegetable seed production is difficult, there are attempts and efforts to produce at local level. Strengthening of community based seed multiplication is a means to develop the vegetable seed production techniques and business. In order to bring this to practical, demonstration and scaling up activities conducted since 2009 to 2014 . Farmers Research Group (FRG) approach was used to implement the research. In 2013 an average yield of 7q/ha of onion seed was recorded while the maximum was $10 \mathrm{q} / \mathrm{ha}$. While in 2014 a maximum yield $16 \mathrm{q} / \mathrm{ha}$ was recorded at farmers field. The yield increment might be due to skill development by the farmers. Farmers could get gross income of 24, 000 thousand from a parcel of $300 \mathrm{~m}^{2}$ land. Thus local seed production practice is technically possible and economically feasible and should be encouraged and promoted by all stakeholders so as to enhance the income and livelihood of farmers.
\end{abstract}

Keywords: onion seed, production and yield

\section{Introduction}

Although smallholder farmers produce the bulk of crops, the production and productivity are very low. The main reason is restricted use of inputs, notably improved seeds and fertilizers. The use of seed of poor genetic potential is one of the contributing factors for low productivity. Over $95 \%$ of seed sources come from farm saved seed of non-improved land races.

Different vegetable seeds are imported. There is a danger in relying on imported seed. Imported supplies may be disrupted by political changes; outbreaks of insects and diseases abroad may force the importation of seeds to be banned. Complete reliance on imported seeds may also lead to a dependence on foreign technology. It also may be low quality both genetically and physically (Lemma, 1998).

Vegetable seed production is often very challenging because of strict requirements to maintain genetic integrity of the variety being multiplied, to produce seed of vigor that does not carry seed-borne diseases, and to obtain a seed yield sufficient to make the crop economical for the seed producer. This difficulty is exacerbated by the fact that traits associated with vegetable production and quality, rather than seed production, are selected for in varietal development programs (Peter, 2001).

There is a growing need and effort to develop the seed industry in the country. With the existing planting materials constraint in the country, the research center is making all possible in seed multiplication effort to assist producers. Seed of different vegetable crop varieties are propagated and distributed to different government and none government organizations (Lemma, 2009).

Similar to the other areas of the country, vegetable growing farmers at central Tigray have similar problems of seed supply. On the other hand, there are suitable agro-ecological conditions that favor vegetable seed production including onion. Thus, it is important to develop the seed business by developing appropriate technologies and popularizing to farmers. Since one of the major problems of vegetable production is seed quality and access, it is imminent to produce farmers of the project areas by themselves.

Objective

$>$ To introduce and popularize the available vegetable seed production technology to farmers

$>$ To develop farmer based vegetable seed production system in the community

\section{Materials and Methods \\ Description research sites \\ Maiweini (Mereb Lekhe)}

This area is located about $42 \mathrm{~km}$ north of Adwa town in the Ethio-Eritrea border. The place where the diversion is constructed is considered as low land with an altitude of not lesser than 1500masl. It is potential area for horticultural crops production with a wider diversity. Its farmers grow fruits of tropical types, vegetables, cereals, oil crops and preserve many lowland trees. The diversion is constructed to divert water from the river known as 'Adi-Arbaete'. It covers the irrigation water need of about 50 farmers whose plots are embedded in and around 
the diversion though the number farmers benefited from it reduced in the later time of the season. Famers often grow fruits such as orange, apple mango, mango, banana, papaya, and lemon; vegetables such as tomato, hot pepper, lettuce, onion, and shallot; oil crops such as groundnut and cereals such as sorghum, maize, finger millet, and Teff. Tomato is the major vegetable crop ever grown in small scale irrigation scheme of the diversion.

Misye schme, L.maichew

It is found in central zone of Tigray, $\mathrm{L} /$ michew wereda, Debrekal tabia.

The project site can be accessed from the town Axum to southwest direction about $12 \mathrm{~km}$. The site is accessible easily on the dry season while it is difficult at the rainy season.

\section{The approach and methods}

Each farmer prepared plot size of at least $10 \mathrm{~m}$ by $10 \mathrm{~m}$. An improved onion variety (Bombay red) was used. Farmers was be given a dry bulb or seed as a planting material. A bulb to seed method of production will be used. Meaning, a bulb will be produced as usual either by the farmers themselves or by the research center.

After bulb is matured and harvested a typical quality bulb was selected and vernalized for about two months, then the bulb was planted in the demonstration plot of the farmers in a spacing of $50 \mathrm{~cm}, 30 \mathrm{~cm}$ and 20 $\mathrm{cm}$ of bed, row and plant respectively. Appropriate management including pest protection was given great consideration.

In addition, farmers were given an intensive training about the improved practices of onion production and were exposed to other FRG members in other areas out of the region to share an experience.

\section{Process of FRG establishment}

All the techniques of establishing FRG had been used. This began from selection of members based on their commitment to work in groups. In such case, all farmers benefited from the IFAD diversions had been organized as FRG groups. These farmers were simply organized in to FRG groups. The list of these farmers was obtained from the BoANR of each wereda. Researchers provided training to the farmers about the overall nature of FRG, techniques of Horticultural crops production, efficient use of irrigation water, integrated pest management, Integrated Soil Fertility Management, marketing of horticultural crops and post harvest handling of these crops. Each major group was divided in to sub groups based on the problems identified during the establishment, interest of members and available proven and improved agricultural technologies. Leaders and clerks of the major groups and sub-groups were selected by members during the course of establishment. These groups and sub-groups were named by the major crop based on which members undergone their research activities. One of the sub groups were the onion seed production sub group.

During implementation of the research, the farmers were applying all the necessary improved agronomic practices needed for onion seed production. This was done through close follow up of DAs of the 'Tabia' and with a close supervision of researchers from AxARC.

\section{Results, Achievements and Experiences}

\section{Onion Seed yield in Qt/ha at diffrent farmers}

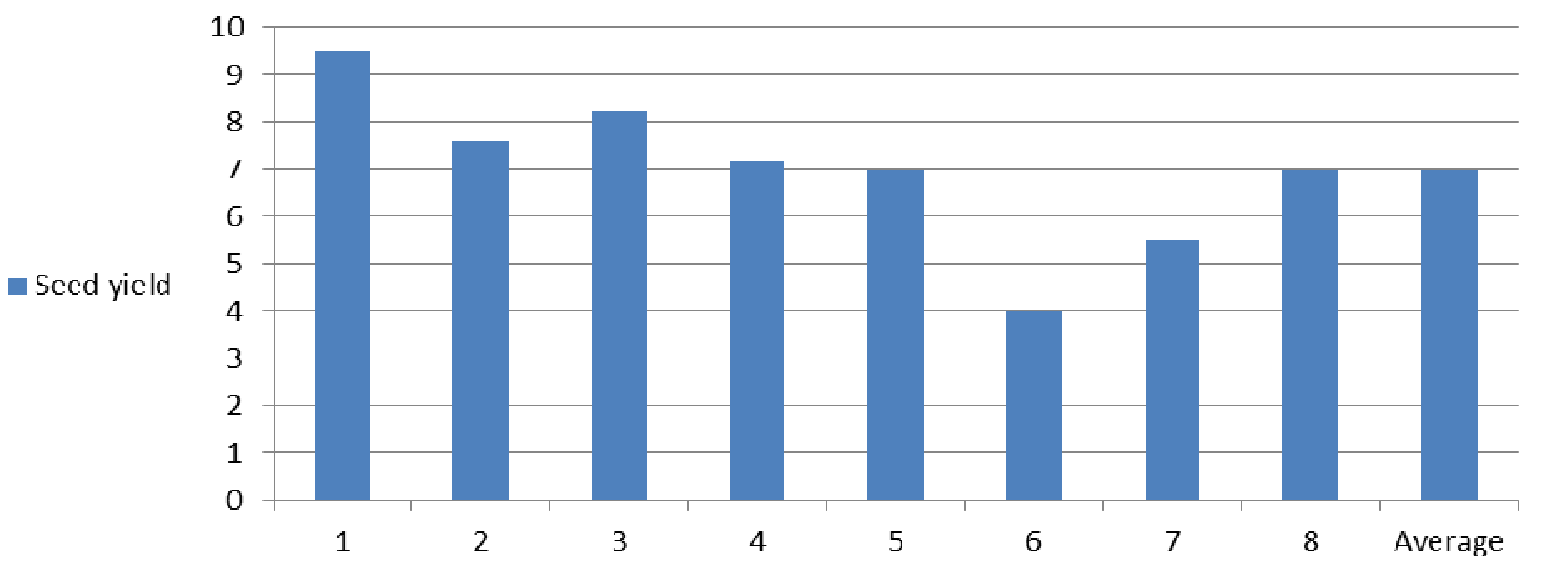

Figure 1 Onion seed production yield of different households in 2013 at Mai sye scheme

As the above graph indicated the farmers harvest an average seed yield of $7 \mathrm{qt} / \mathrm{ha}$ while the maximum yield reached about $10 \mathrm{qt} / \mathrm{ha}$ which is near the potential of the crop. The average yield decrement may be due to the poor handling of farmers due to the fact that the technology is new to the area. According to Lemma, et al (2006), onion seed production can ranged from 10 to $13 \mathrm{qt} / \mathrm{ha}$. This implies that the seed production potential of the areas is comparable to the national potential in productivity per unit area. 


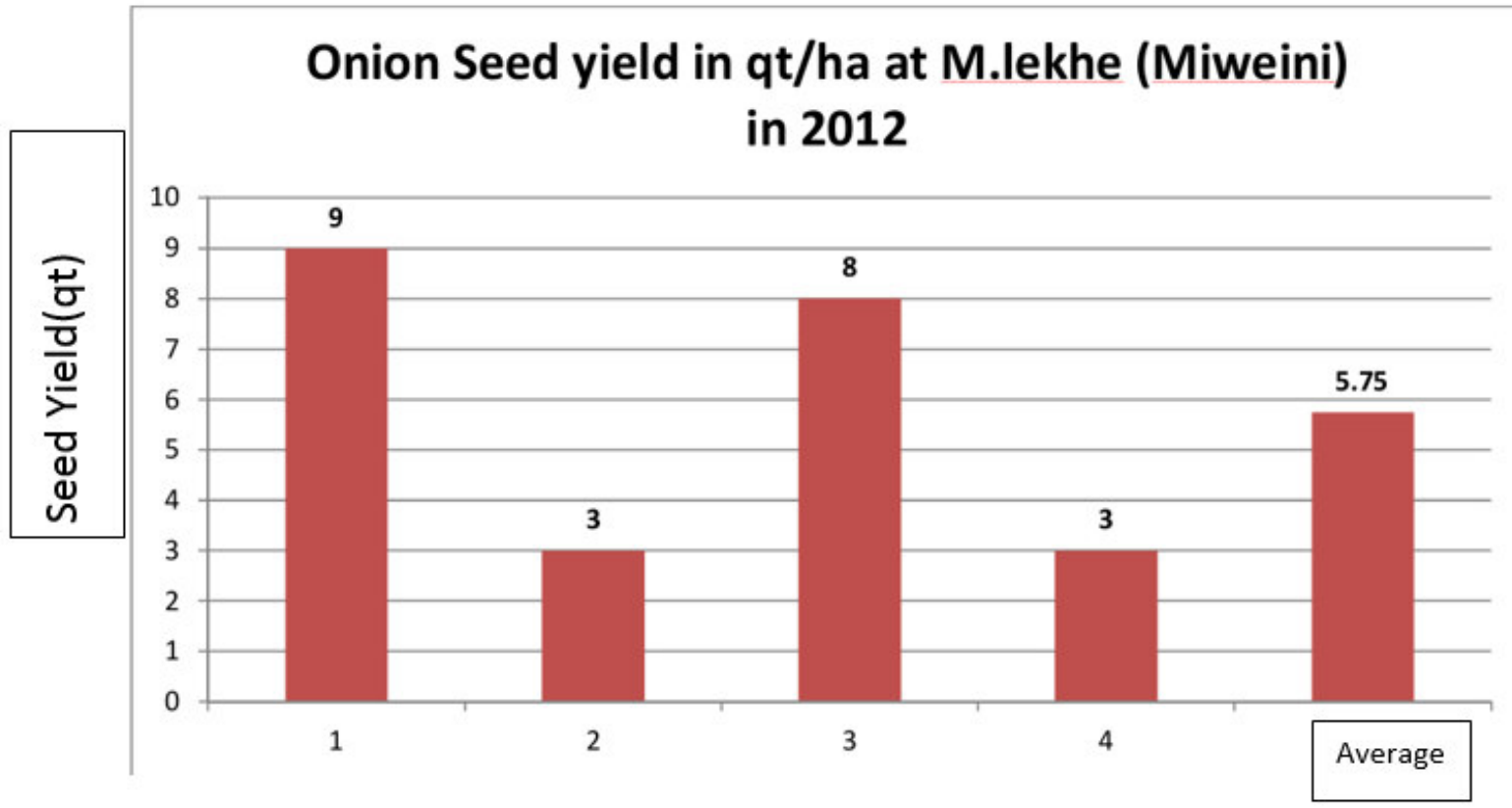

Figure 2 Onion seed production yield of different households in 2012 at Mai weini (M/lekhe) and May sye (L.maichew) schemes

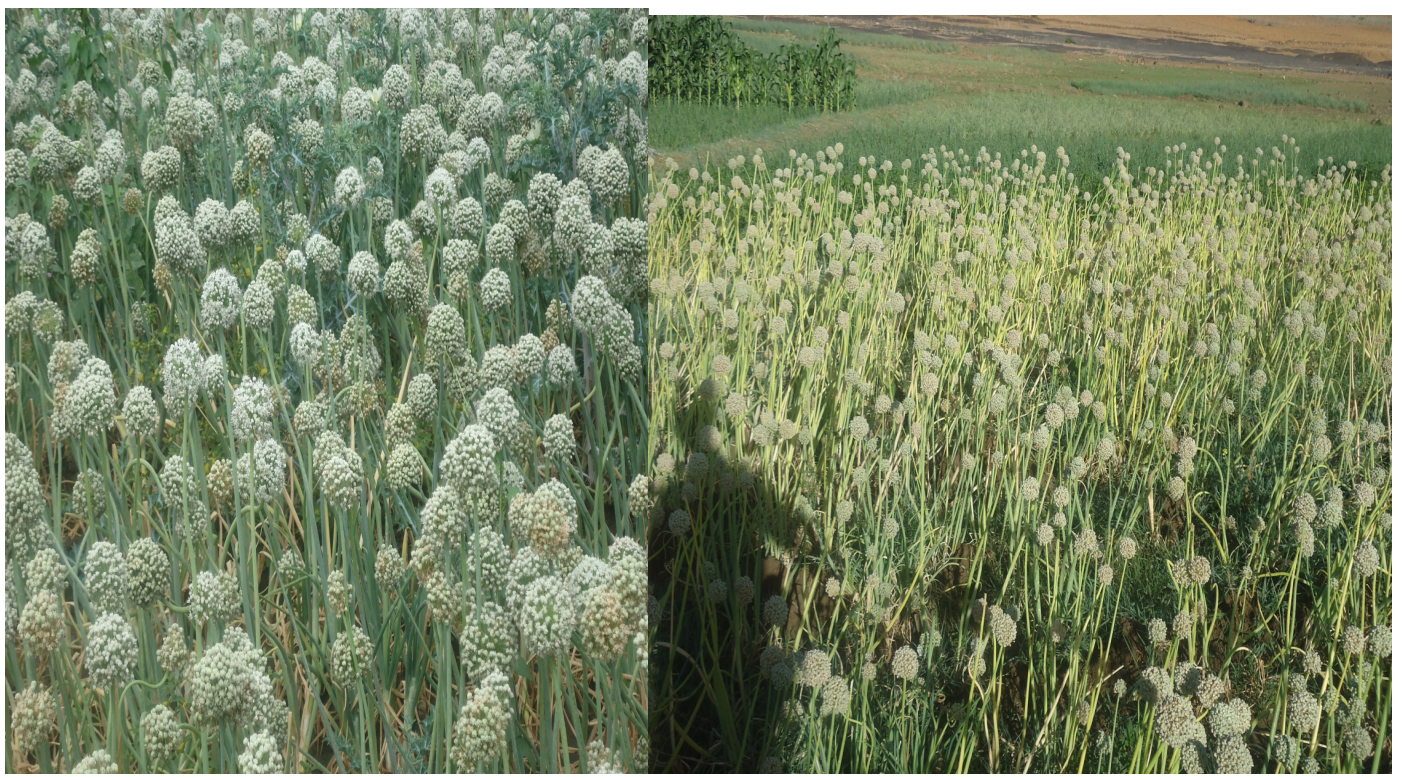

Figure 3. Onion production plots at M.lekhe (left and L.maichew (right) 


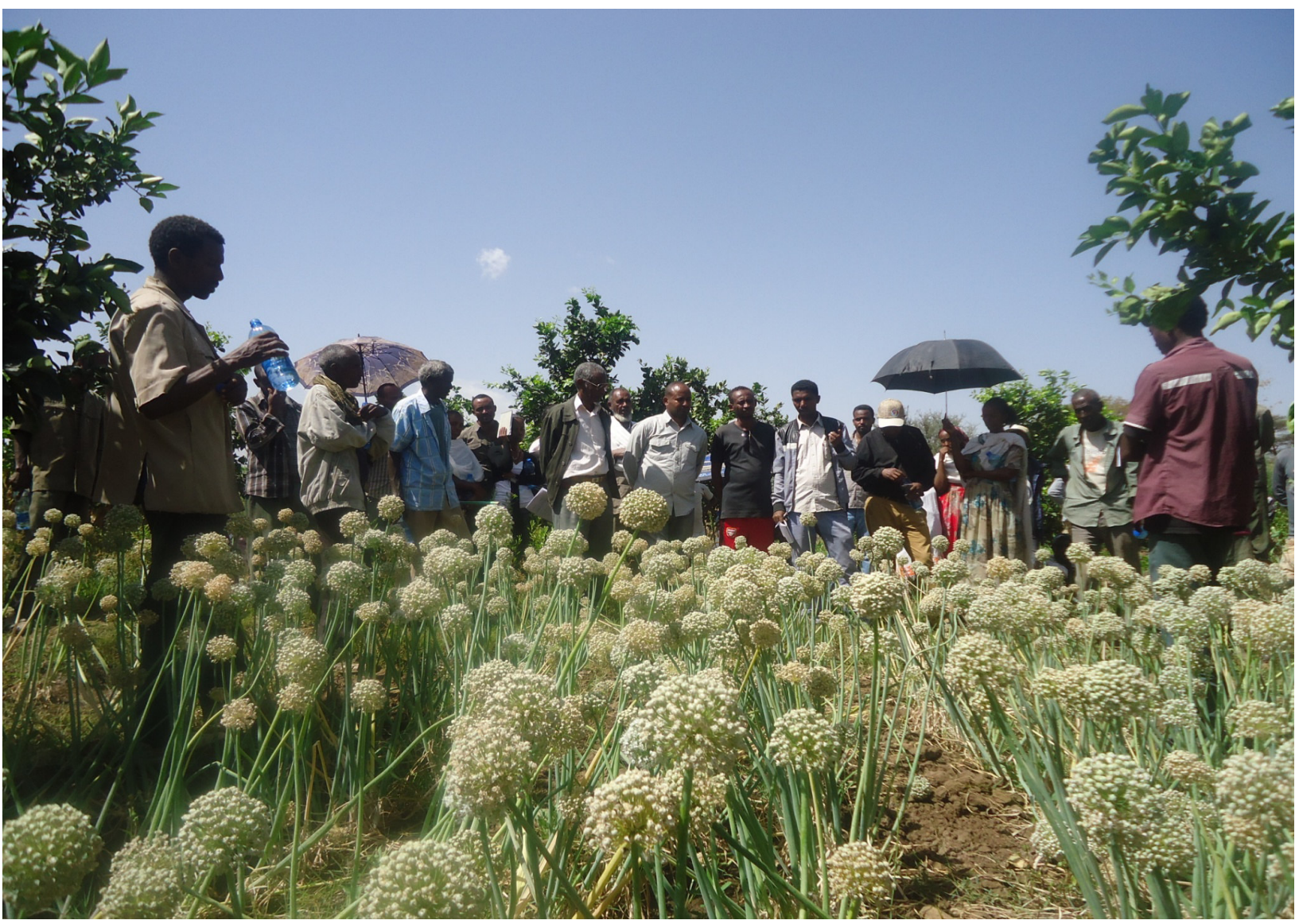

Figure 4. Stakeholders evaluation of the technologies at M.lekhe 2012 at field day

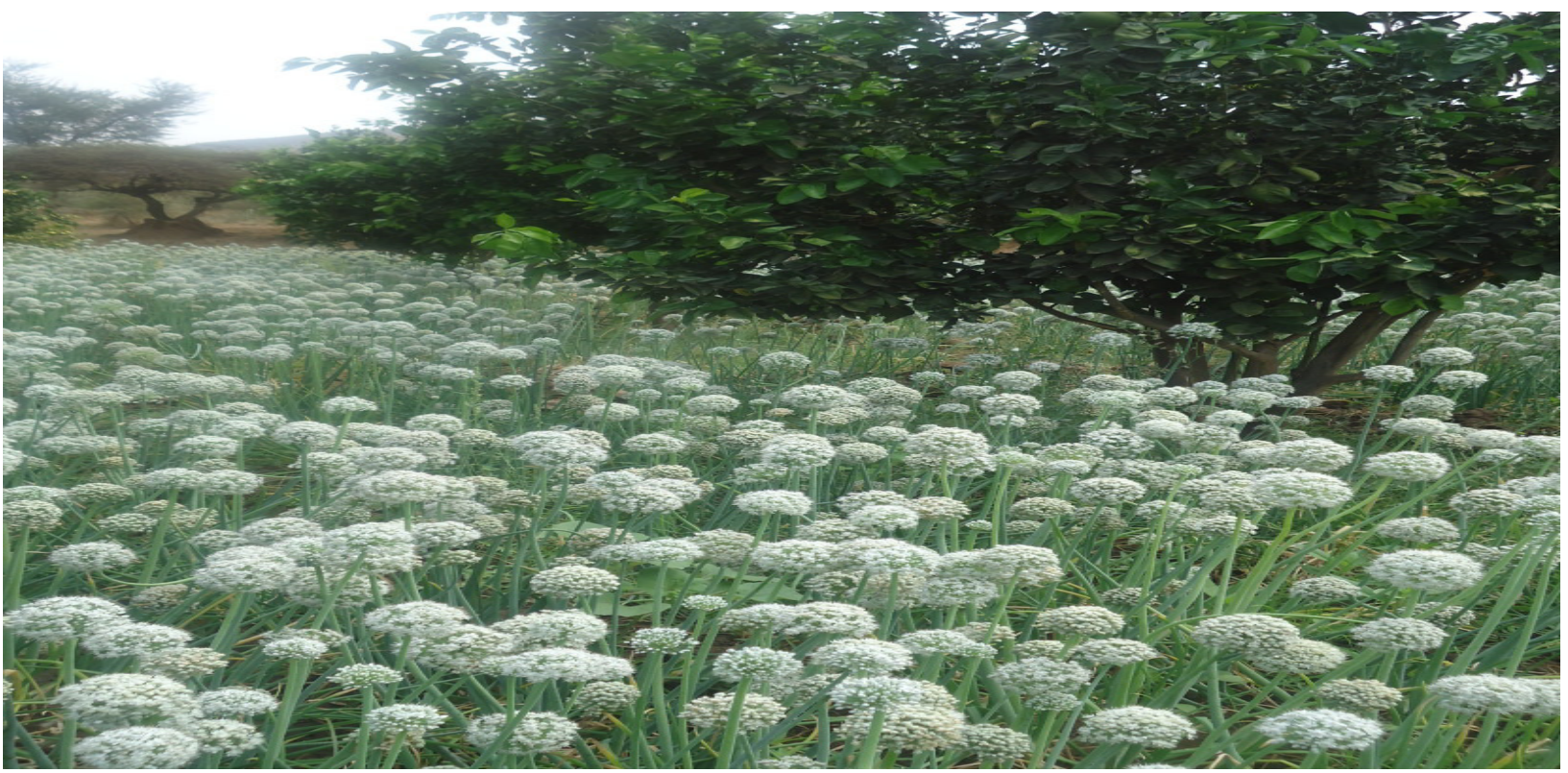

Figure 5 Onion seed production plots inter cropped with orange fruit at M.lekhe

According the stakeholders view; the onion variety given for onion seed production purpose was well adapted in our environment and gave good quality seed. This kind of research is important to familiarize the community in onion seed production techniques as well as helps to produce and maintain pure quality of seed by ourselves. Farmers and stakeholders explained that there is a threat of disease introduction through illegal seed market from unknown source. So this local seed production system can reduce this risk. Adequacy and quality of vegetable seeds are crucial for increased production. This means thatthe seed of needed traits should be timely acquired from reliable sources to ensure high determination and increased yield. The problem of lack orshortage of appropriate type of improved seeds of vegetables which are needed by the market (Emana 
and Gebremedhin, 2007).

The Ethiopian seed industry is composed of formal and informal sectors as well as public and private organization. The formal sectors include federal and regional agricultural research establishments, universities, the regulatory organ in the MoARD, and private companies. The informal sectors encompass millions of farmers, who continue to practice seed selection and preservation, just as their ancestors did (Kebede , 2009). The formal system is concerned with the development and distribution of seeds of modern or improved varieties, while local cultivars or landrace varieties are handled by the informal system.

The onion seed production technology is very appreciable and should be scale out. The farmers approved it is economically feasible and profitable in all three schemes. The collaboration effort of stakeholders (GOs and NGOs) together with AxARC and Extension office is immense. Efficiency of Farmers' research group to demonstrate and transfer of technology was practically observed. It is also true that there are variety evaluation and development on vegetables which complements the package of seed production and the whole value chain. Since the activities started in 2010 considerable numbers of farmers have been benefited from purchasing the locally produced seeds of onion.

More over it can be concluded that the onion seed production technology is possible and feasible at the local level and important for increasing seed availability in quantity and quality, as means of good income generating commodity and protection of threat diseases. Thus local seed production practice should be encouraged and promoted by all stakeholders so as to enhance the income and livelihood of farmers.

\section{References}

Emana, B., and Gebremedhin, H., Constraints and Opportunities of Horticulture Production and Marketing in Eastern Ethiopia. Drylands Coordination Group Report No. $46(02,2007)$

Kebede Tafesse.2009.Towarde Seed Industry Development In Ethiopia. National Seed Industry Agency, Addis Ababa Ethiopia

Lemma D. 2004. Onion Production Pamphlet (Amharic version). EARO, Melkassa Agricultural Research Center.

Lemma Dessalegne, Shimeles Aklilu, Selamawit Ketema, and Chimdo Anchala, 2006. The Vegetable Seed Sector in Ethiopia: Current Status and Future Prospects. EHSS, Proceedings of the Inaugural and Third National Horticultural Workshop, Ethiopia. Volume 1. 103-109.

Peter Sexton.2001.Vegetable Seed Production 2nd Edition. CABI Publishing. New York 